\title{
Reconstruction of Spinal Soft Tissue Defects With Perforator Flaps From the Paraspinal Region
}

\author{
PIETRO G. DI SUMMA ${ }^{1}$, RENÉ D. LARGO ${ }^{2}$, TAREK ISMAIL ${ }^{2}$, MATHIAS TREMP $^{2}$, ALEXANDER LUNGER $^{2}$, \\ RETO WETTSTEIN ${ }^{2}$, SWENN MAXENCE KRÄHENBÜHL ${ }^{1}$, SALVATORE GIORDANO ${ }^{3}$, \\ DIRK J. SCHAEFER ${ }^{2}$, STEFAN SCHAEREN ${ }^{4}$ and DANIEL F. KALBERMATTEN ${ }^{2}$ \\ ${ }^{1}$ Division of Plastic, Reconstructive \& Aesthetic Surgery, CHUV, \\ University Hospital of Lausanne, Lausanne, Switzerland; \\ ${ }^{2}$ Department of Plastic, Reconstructive, Aesthetic and Hand Surgery, University Hospital Basel, Basel, Switzerland; \\ ${ }^{3}$ Department of Plastic and General Surgery, Turku University Hospital, Turku, Finland; \\ ${ }^{4}$ Department of Spinal Surgery, University Hospital of Basel, Basel, Switzerland
}

\begin{abstract}
Background/Aim: Reconstruction of spinal soft tissue defects is challenging, especially when neural structures or prosthetic material are exposed. They should be covered with well-vascularized tissue such as paraspinal perforator flaps. Materials and Methods: This is a retrospective study of soft tissue reconstructions with paraspinal perforator flaps from 2011 to 2018. The technique is described and risk factors for poor wound healing were assessed. Postoperative complications are reported. Results: Twenty patients with a mean age of 63.65 years were included. Defects had an average size of $47 \mathrm{~cm}^{2}$ and were mainly located in the lumbosacral region ( 9 patients). Twelve patients suffered from infection following spinal stabilization, seven of whom were diagnosed with osteomyelitis, two patients presented with pressure sore and one patient experienced wound dehiscence. One partial flap necrosis with a lumbar defect occurred, which required revision surgery. No total flap loss occurred. Stable, closed wounds were achieved at their final follow-up. Conclusion: Perforator paraspinal flaps are suitable for immediate reconstruction of spinal defects.
\end{abstract}

Posterior trunk soft tissue defects represent a reconstructive challenge, especially in the case of exposed vertebral

This article is freely accessible online.

Correspondence to: Daniel F. Kalbermatten, MD, PhD, Plastic, Reconstructive, Aesthetic and Hand Surgery, University Basel, Spitalstrasse 21, 4031 Basel, Switzerland. Tel: +41 612652525, Fax: +41 612657301, e-mail: daniel.kalbermatten@usb.ch

Key Words: Dorsal midline defect, osteomyelitis, fasciocutaneous flaps. hardware, spinal cord and cerebrospinal fluid leakage. Defects can derive from trauma, tumor resection or debridement following postoperative infections. Indeed, wound dehiscence following spinal surgery, which particularly strikes on polymorbid or cachectic patients, may finally lead to deep infections with the frightening risk of osteomyelitis.

The ideal treatment includes effective debridement and defect coverage with well-vascularized tissue that obliterates dead space. Conventional treatment options have mainly focused on muscle or myocutaneous flaps, such as trapezius or latissimus dorsi muscle flaps, although their significant donor site morbidity represents a well-known disadvantage (1). In the era of perforator flaps, surgeons have largely searched for evidence regarding whether muscle or myocutaneous flaps should be preferred to fasciocutaneous flaps to prevent infections (2). On the other hand, a clear advantage of perforator flaps is the reduced donor site morbidity (3). The present study aimed to assess feasibility and reliability of perforator flaps from the paraspinal region for coverage of complex spinal defects, and their long-term outcomes.

\section{Materials and Methods}

Twenty consecutive patients suffering from spinal soft tissue defects underwent soft tissue reconstruction with perforator flaps from the paraspinal region between 2011 and 2018 (Table I). A retrospective analysis was performed on a prospectively maintained database. Spinal soft tissue defects were present in the cervical, thoracic, lumbar and sacral regions due to vertebral stabilization, tumor resection or debridement following postoperative infections (wound dehiscence, infection and secondary osteomyelitis). Risk factors such as smoking, obesity, steroids, hypertension, collagen-vascular diseases, paralysis, and malnutrition were, together with defect characteristics (size, localization) and duration of surgery are shown in Table II. 
Table I. Patients characteristics and demographics.

Patients (n)

Age (y)

Etiology of defect (n, \%)

\author{
20 (11 male, 9 female) \\ 63.65 (26-86) \\ Complication after spinal stabilization $(\mathrm{n}=15,75 \%)$ \\ - 12 infection (7 including osteomyelitis) \\ - 2 pressure sore \\ - 1 wound dehiscence \\ Other $(\mathrm{n}=5,25 \%)$ \\ - 3 tumor resections (melanoma, sarcoma) \\ - 2 internal iliac artery compromise \\ $5,25 \%$ \\ $3,15 \%$ \\ $1,5 \%$
}

Hardware exposure (n, \%)

Dural exposure (n, \%)

CSF leak (n \%)
Table II. Risk factors for wound complication. Risk factors for wound complications (major and minor) together with wound characteristics (localization and size). Duration of the surgery for reconstruction.

\begin{tabular}{lc}
\hline Risk factor & Patients \\
\hline Smoking (n, \%) & $6,30 \%$ \\
Obesity (n, \%) & $5,25 \%$ \\
Steroids (n, \%) & $3,15 \%$ \\
Hypertension (n, \%) & $7,35 \%$ \\
Collagen - vascular disease (n, \%) & $1,5 \%$ \\
Palsy (n, \%) & $3,15 \%$ \\
Malnutrition (n, \%) & $8,35 \%$ \\
Diabetes (n, \%) & $6,30 \%$ \\
Defect location (n, \%) & $3,15 \%$ cervical \\
& $8,40 \%$ thoracal \\
Defect size (cm 2 ) & $9,45 \%$ lumbosacral \\
Duration of surgery (min) & 47 (9-150) \\
\hline
\end{tabular}

CSF: Cerebrospinal fluid.

\section{Results}

Twenty consecutive patients (11 male, 9 female) with a mean age of 63.65 years (range $=26-86$ years) with spinal soft tissue defects treated with perforator flaps from the paraspinal region between 2011 and 2018 were included into the study (Table I). Defects averaged $47 \mathrm{~cm}^{2}$ (range $=9-150 \mathrm{~cm}^{2}$ ) in size and were mainly located in the lumbosacral region (9 patients, $45 \%$ ) followed by the thoracic region ( 8 patients, $40 \%$ ) and the cervical region (3 patients, 15\%). Hardware was exposed in five patients. Three patients suffered from exposed dura and one patient from CSF leakage. Etiology of the spinal soft tissue defects was mainly postoperative early infection following spinal stabilization (12 patients, 60\%). Among the eleven patients that developed infection, seven patients had osteomyelitis (Table I). 
Minor complications (n) (hematoma, seroma, infection, skin slough, partial flap necrosis and wound dehiscence)

Major complications (n) (total flap loss, need for reoperation)

Hardware removal $(\mathrm{n})$

Antibiotic treatment (weeks)

Hospitalization time after flap reconstruction (days)

Hospitalization time (days)

Length of follow-up (months)

$$
\begin{gathered}
5,25 \% \\
1,5 \% \\
0 \\
7.8(1-15) \\
20.05(3-36) \\
28.75(6-68) \\
13.4(2-20)
\end{gathered}
$$

Malnutrition (8 patients, 40\%), hypertension (7 patients, $35 \%$ ) and smoking (6 patients, $30 \%$ ) were the most common risk factors among the study population (Table II). Analysis revealed 16 out of 20 patients $(80 \%)$ with 2 or more risk factors for poor wound healing (Figure 3).

Average duration of surgery (reconstruction) was $153 \mathrm{~min}$ (45-367 minutes). Mean follow-up was 13.4 months (range $=4-20$ months). Minor complications occurred in five patients (25\%, Table III). Only one wound dehiscence was observed. A partial distal flap loss (major complication) was observed in one patient requiring revision surgery with debridement and further advancement of the perforator flap. No total flap loss occurred. No hardware removal or change was necessary. Mean antibiotic treatment was 7.8 weeks (range $=0-15$ weeks) after defect closure. Duration of the total hospital stay averaged 28.75 days (range=6-68 days), whereas the average hospital stay after reconstruction was 20.05 days (range $=3-36$ days) (Table III).

\section{Discussion}

Complex midline back soft tissue defects are traditionally treated with muscle or myocutaneous flaps, due to earlier experimental studies suggesting the superiority of muscle flaps compared to random pattern fasciocutaneous flaps in treating infected wounds $(4,5)$. Furthermore, muscle flaps may guarantee pliability and the advantage to better fill the dead space. However, muscle flaps can frequently lead to significant donor site morbidity, which often requires complementary skin graft (6).

Perforator flaps extend the reconstructive armamentarium while preserving muscle function and subsequently minimize donor site morbidity (7-9). Perforator flaps rely on a vascular pedicle that leads to the overlying fascia or skin only. Each perforator has its own and reliable arterial vascular territory "perforasome" which are linked with adjacent perforasomes by "linking vessels" (10). The flap design, therefore, depends on the size of the perforasome of the perforator. Experimental work in a rabbit model showed no statistical difference in wound healing in superficial and deep infections between latissimus dorsi musculocutaneous flaps and thoracodorsal artery perforator based fasciocutaneous flaps. Various clinical studies using perforator flaps challenged the notion that infected wounds or osteomyelitis should be covered with muscle tissue $(11,12)$. These studies concluded that the type of flap used for reconstruction, is less critical for the final outcome if basic concepts of radical debridement of necrotic and infected tissue and the need for dead space obliteration were respected.

Perforator flaps from the paraspinal cervico-thoracolumbar region for spinal defect coverage ideally follow the "like with like" tissue replacement principle of plastic surgery. These flaps are nourished by medial and lateral dorsal cutaneous branches of the intercostal artery, that supply the spinalis and longissimus muscle before reaching the skin, just lateral to the spinous processes. Minabe et al. found nine pairs of dorsal intercostal artery perforators (DICAPs) measuring 0.5 to $1 \mathrm{~mm}$ in diameter within $5 \mathrm{~cm}$ of the spinous processes (8). Perforator flaps from the paraspinal region in the upper thoracic area can be extended up to the anterior border of the latissimus dorsi muscle, due to choke anastomoses with the scapular circumflex artery and cutaneous branches of the thoracodorsal artery. Similarly, in the lower thoracolumbar part, perforator flaps can be harvested to the iliac crest due to choke anastomoses with lumbar arteries and/or the thoracodorsal artery. In between the seventh and ninth vertebral body, musculocutaneous perforators from the paraspinous muscle are more dominant than the DICAP of the same level supplying the middle back skin. The length of the perforator was $1-3 \mathrm{~cm}$ subfascially for upper DICAP and 4-10 cm of length for the lower DICAP, respectively. Furthermore, De Weerd et al. introduced the sensate DICAP flap for closure of cervicothoracic midline defects after spinal surgery, which was raised longitudinally from lateral to medial (13). In a cadaveric study, the authors found a reliable course of the medial DICAP and all of the medial and lateral DICAPs were accompanied by a cutaneous nerve, providing protective sensibility to the reconstructed area. This would serve as an advantage of the perforator flap compared to muscle flap options.

In our hands, soft tissue defects of the posterior trunk or spinal area can be successfully treated using paraspinal 

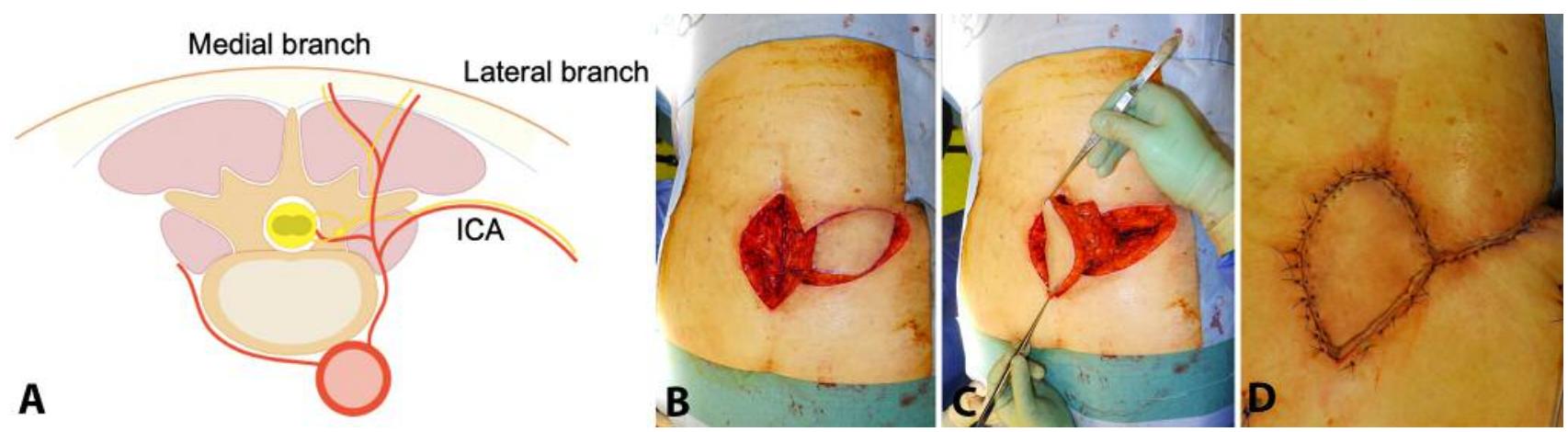

Figure 1. Paraspinal perforators vascularization. (A) Scheme of the paraspinal perforators originating from the dorsal intercostal artery (DICA) and splitting in a medial and lateral branch. (B) Intraoperative images of a lumbal spinal defect with a paraspinal perforator flap dissected and rotated $90^{\circ}$ for defect closure.
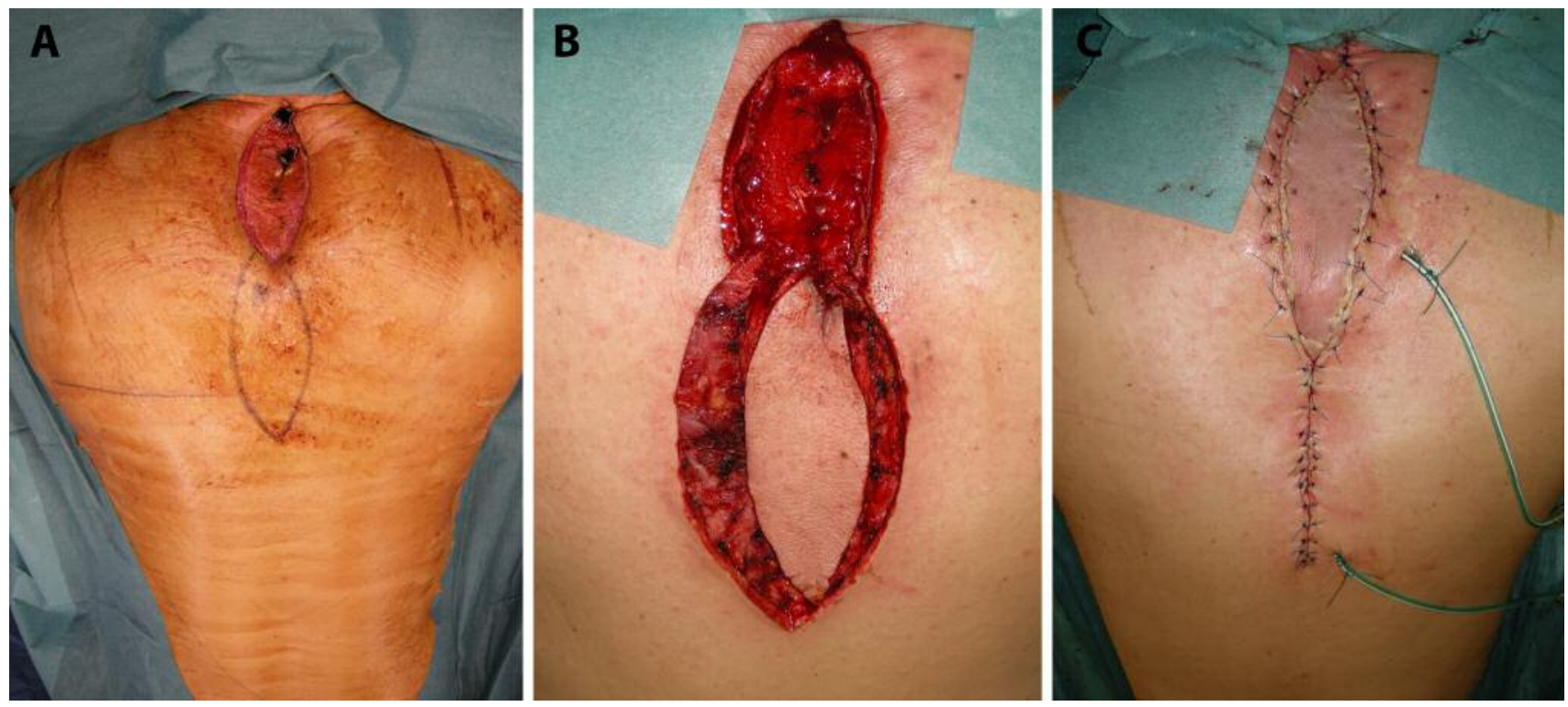

Figure 2. Operative pictures. Intraoperative pictures from male patient with a cervical spine defect after fusion. (A) Paraspinal perforator flap is designed and $(B)$ harvested and rotated $180^{\circ}$ for defect closures $(C)$.

perforator flaps with low donor site morbidity. In our retrospective study including 20 patients, we observed a similar complication rate in paraspinal perforator flaps compared to muscle flap coverage (14). From our experience, complete dissection of perforators should be minimized in flap rotation is less than $90^{\circ}$. A skin bridge of the flap should be preserved whenever possible to increase lymphatic and venous drainage. If a flap rotation of more than $90^{\circ}$ is needed, the vascular pedicel should be dissected as far down to the source vessel as necessary, to allow the torsion of the pedicle to be distributed over a longer distance. Soft tissue defects of the present study had an average size of $47 \mathrm{~cm}^{2}$ with a range from 9 to $150 \mathrm{~cm}^{2}$. According to Prasad et al., maximum flap dimension of perforator flaps from the paraspinal (DICAP) region might be up to $40 \times 15 \mathrm{~cm}$ (15). Similar studies, even if based on smaller series, report the use of paraspinal flaps to cover posterior trunk defects $(16,17)$. Their overall flap complication rate ranged between $0 \%$ and $42.8 \%$, including all types of complications (major and minor together). In the present study, we report an overall complication rate of $30 \%$ (including both minor and minor complications), with only $5 \%$ of patients requiring further surgery (Table III).

These previous studies evaluated the feasibility of perforator-based flaps mostly in defects occurring after tumor resection. Our study population consisted mostly of spinal surgery wounds with implanted hardware. 


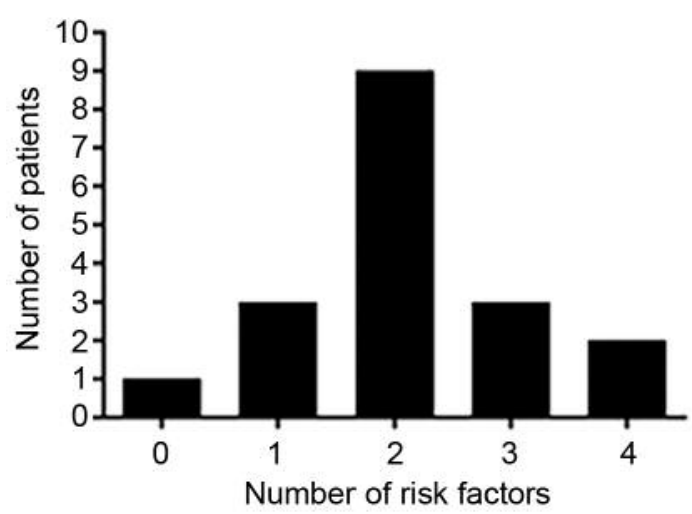

Figure 3. Distribution of risk factors. Most patients had at least 2 risk factors (smoking, obesity, steroids, hypertension, collagen - vascular disease, palsy, malnutrition, diabetes).

Spinal surgery often involves implantation of foreign material. In contrast to extremity reconstruction, perseveration of the hardware is often inevitable, due to lack of therapeutic alternatives, which would ensure stability of the spine (18). This makes subsequent treatment of infections particularly challenging (19).

Indeed, hardware removal in case of deep wound infection remains controversial. Studies have shown that early onset exposed hardware (within one month after initial spinal surgery) with deep infections can be retained, whereas in late onset ( $>1$ month) deep infections, complete hardware removal seems to have a superior outcome (20-22). Duration of infection and hardware exposure are relevant prognostic factors for the salvage of exposed hardware covered with soft tissue (23). In this sense, debridement of the infected wound should be fulfilled within 2 weeks after signs of infection (24), and coverage of a wound with exposed hardware should occur within 3 weeks (25).

In our series, only early infections were present. Debridement and reconstruction of the defect occurred within a maximum of 10 days. No hardware removal was performed. Our study supports the use of perforator flaps applied to spinal defects as a treatment option even in case of early-stage hardware exposure ( $<1$ month).

In our series, we exclusively performed delayed defect restoration. Most recent articles propose prophylactic (immediate) wound coverage with well-vascularized tissue in high-risk patients, to decrease the incidence of postoperative wound healing complications after spinal surgery $(4,14)$. In published studies regarding benefits of immediate reconstruction, mostly muscle flaps were used for defect closure $(4,18,26)$. We feel that further studies about the feasibility of immediate reconstruction with perforator flaps should be conducted.
The main drawback for the present study is the relatively small number of patients and its retrospective design. A disadvantage of perforator flaps from the paraspinal region is their limited value in filling dead space, especially in the cervicothoracic region. Partial de-epithelialization of the flap may provide additional volume to fill a cavitary lesion and in part overcome this limitation. In case of perforator flap failure or soft tissue defect recurrence, perforator flaps from the contralateral paraspinal region or underlying paraspinal muscle flaps could be harvested as a secondary reconstructive option. Moreover, such flaps do not exclude the possibility of harvesting axial myocutaneous flaps (e.g. trapeze), increasing in this way the armamentarium of the reconstructive surgeon is such complex clinical scenarios.

\section{Conclusion}

Perforator flaps from the paraspinal region can provide a valid alternative for patients with comorbidities, even in case of hardware exposure. We recommend the preoperative assessment of perforator position and size by Doppler probe or angiographic CT scan/MRI in complex situations for optimal flap design planning. The perforator flaps from the paraspinal region are dissected fast, rely on constant perforators and have minor donor site morbidity.

\section{Conflicts of Interest}

The Authors declare that they have no conflicts of interest regarding this study.

\section{Authors' Contributions}

Pietre G. di Summa (PGDS), René D. Largo (RDL), Tarek Ismail (TI) and Swenn Maxence Krähenbühl (SMK) were responsible for drafting the manuscript. PGDS, RDL, Stefan Schaeren (SS) and Daniel F. Kalbermatten (DFK) were responsible for the surgical intervention provided to the patients. PGDS, RDL, TI, Mathias Tremp (MT), Alexander Lunger (AL), Reto Wettstein (RW), SMK, Salvatore Giordano (SD), Dirk J. Schaefer (DJS), SS and DFK were responsible for the critical review and correction of the manuscript.

\section{References}

1 Mericli AF, Tarola NA, Moore JH Jr., Copit SE, Fox JWt and Tuma GA: Paraspinous muscle flap reconstruction of complex midline back wounds: Risk factors and postreconstruction complications. Ann Plast Surg 65: 219-224, 2010. PMID: 20585231. DOI: 10.1097/SAP.0b013e3181c47ef4

2 Hong JPJ, Goh TLH, Choi DH, Kim JJ and Suh HS: The efficacy of perforator flaps in the treatment of chronic osteomyelitis. Plast Reconstr Surg 140: 179-188, 2017. PMID: 28654608. DOI: 10.1097/PRS.0000000000003460

3 Geddes CR, Morris SF and Neligan PC: Perforator flaps: Evolution, classification, and applications. Ann Plast Surg 50: 90-99, 2003. PMID: 12545116. DOI: 10.1097/01.SAP.00000 32309.30122 .55 
4 Garvey PB, Rhines LD, Dong W and Chang DW: Immediate soft-tissue reconstruction for complex defects of the spine following surgery for spinal neoplasms. Plast Reconstr Surg 125: 460-466, 2010. PMID: 20134362. DOI: 10.1097/PRS.0b0 $13 \mathrm{e} 3181 \mathrm{~d} 5125 \mathrm{e}$

5 Arnold PG, Yugueros P and Hanssen AD: Muscle flaps in osteomyelitis of the lower extremity: A 20-year account. Plast Reconstr Surg 107: 107-110, 1999. PMID: 10597682

6 May JW Jr. and Rohrich RJ: Foot reconstruction using free microvascular muscle flaps with skin grafts. Clin Plast Surg 13: 681-689, 1986. PMID: 3533377

7 Kroll SS and Rosenfield L: Perforator-based flaps for low posterior midline defects. Plast Reconstr Surg 81: 561-566, 1988. PMID: 3279442

8 Minabe T and Harii K: Dorsal intercostal artery perforator flap: anatomical study and clinical applications. Plast Reconstr Surg 120: 681-689, 2007. PMID: 17700119. DOI: 10.1097/01.prs.00 00270309.33069.e5

9 Roche NA, Van Landuyt K, Blondeel PN, Matton G and Monstrey SJ: The use of pedicled perforator flaps for reconstruction of lumbosacral defects. Ann Plast Surg 45: 7-14, 2000. PMID: 10917091

10 Saint-Cyr M, Wong C, Schaverien M, Mojallal A and Rohrich $\mathrm{RJ}$ : The perforasome theory: vascular anatomy and clinical implications. Plast Reconstr Surg 124: 1529-1544, 2009. PMID: 20009839. DOI: 10.1097/PRS.0b013e3181b98a6c

11 Guerra AB, Gill PS, Trahan CG, Ruiz B, Lund KM, Delaune CL, Thibodeaux BA and Metzinger SE: Comparison of bacterial inoculation and transcutaneous oxygen tension in the rabbit $\mathrm{S} 1$ perforator and latissimus dorsi musculocutaneous flaps. J Reconstr Microsurg 21: 137-143, 2005. PMID: 15739152. DOI: $10.1055 / \mathrm{s}-2005-864848$

12 Zweifel-Schlatter M, Haug M, Schaefer DJ, Wolfinger E, Ochsner P and Pierer G: Free fasciocutaneous flaps in the treatment of chronic osteomyelitis of the tibia: A retrospective study. J Reconstr Microsurg 22: 41-47, 2006. PMID: 16425121. DOI: $10.1055 / \mathrm{s}-2006-931906$

13 de Weerd L and Weum S: The sensate medial dorsal intercostal artery perforator flap for closure of cervicothoracic midline defects after spinal surgery: an anatomic study and case reports. Ann Plast Surg 63: 418-421, 2009. PMID: 19745704. DOI: 10.1097/SAP.0b013e31819537b4

14 Chieng LO, Hubbard Z, Salgado CJ, Levi AD and Chim H: Reconstruction of open wounds as a complication of spinal surgery with flaps: A systematic review. Neurosurg Focus 39: E17, 2015. PMID: 26424341. DOI: 10.3171/2015.7.FOCUS15245

15 Prasad V and Morris SF: Propeller DICAP flap for a large defect on the back-case report and review of the literature. Microsurgery 32: 617-621, 2012. PMID: 23059834. DOI: $10.1002 /$ micr.22039

16 Brunetti B, Tenna S, Aveta A, Poccia I, Segreto F, Cerbone V and Persichetti P: Posterior trunk reconstruction with the dorsal intercostal artery perforator based flap: Clinical experience on 20 consecutive oncological cases. Microsurgery 36: 546-551, 2016. PMID: 25821103. DOI: 10.1002/micr.22408
17 Zang M, Yu S, Xu L, Zhao Z, Zhu S, Ding Q and Liu Y: Intercostal artery perforator propeller flap for reconstruction of trunk defects following sarcoma resection. J Plast Reconstr Aesthet Surg 68: 822-829, 2015. PMID: 25801799. DOI: 10.1016/j.bjps.2015.02.009

18 Dumanian GA, Ondra SL, Liu J, Schafer MF and Chao JD: Muscle flap salvage of spine wounds with soft tissue defects or infection. Spine (Phila Pa 1976) 28: 1203-1211, 2003. PMID: 12782993. DOI: $10.1097 / 01 . B R S .0000067260 .22943 .48$

19 Metsemakers WJ, Kuehl R, Moriarty TF, Richards RG, Verhofstad MHJ, Borens $\mathrm{O}$, Kates $\mathrm{S}$ and Morgenstern M: Infection after fracture fixation: Current surgical and microbiological concepts. Injury 49: 511-522, 2018. PMID: 27639601. DOI: 10.1016/j.injury.2016.09.019

20 Lall RR, Wong AP, Lall RR, Lawton CD, Smith ZA and Dahdaleh NS: Evidence-based management of deep wound infection after spinal instrumentation. J Clin Neurosci 22: 238242, 2015. PMID: 25308619. DOI: 10.1016/j.jocn.2014.07.010

21 Kowalski TJ, Berbari EF, Huddleston PM, Steckelberg JM, Mandrekar JN and Osmon DR: The management and outcome of spinal implant infections: contemporary retrospective cohort study. Clin Infect Dis 44: 913-920, 2007. PMID: 17342641. DOI: $10.1086 / 512194$

22 Hultman CS, Jones GE, Losken A, Seify H, Schaefer TG, Zapiach LA and Carlson GW: Salvage of infected spinal hardware with paraspinous muscle flaps: anatomic considerations with clinical correlation. Ann Plast Surg 57: 521-528, 2006. PMID: 17060733. DOI: 10.1097/01.sap.00002 26931.23076.a7

23 Viol A, Pradka SP, Baumeister SP, Wang D, Moyer KE, Zura RD, Olson SA, Zenn MR, Levin SL and Erdmann D: Soft-tissue defects and exposed hardware: a review of indications for softtissue reconstruction and hardware preservation. Plast Reconstr Surg 123: 1256-1263, 2009. PMID: 19337094. DOI: 10.1097/ PRS.0b013e31819f2b5e

24 Crockarell JR, Hanssen AD, Osmon DR and Morrey BF: Treatment of infection with debridement and retention of the components following hip arthroplasty. J Bone Joint Surg Am 80: 1306-1313, 1998. PMID: 9759815

25 Greenberg B, LaRossa D, Lotke PA, Murphy JB and Noone RB: Salvage of jeopardized total-knee prosthesis: the role of the gastrocnemius muscle flap. Plast Reconstr Surg 83: 85-89, 1989. PMID: 2909081

26 Chang DW, Friel MT and Youssef AA: Reconstructive strategies in soft tissue reconstruction after resection of spinal neoplasms. Spine (Phila Pa 1976) 32: 1101-1106, 2007. PMID: 17471093. DOI: $10.1097 / 01 . b r s .0000261555 .72265 .3 \mathrm{f}$

Received January 31, 2019

Revised February 27, 2019 Accepted March 1, 2019 